\title{
Manuscript Runes from the North of England: The Byland Bede
}

\author{
Aya M. S. Van Renterghem (Leiden University)
}

\begin{abstract}
This article presents the new find of a manuscript with runes from Byland in Yorkshire. It provides a full description of the manuscript and examines its Scandinavian runic alphabet in detail. The runes are further assessed within the context of the English tradition of runica manuscripta and Scandinavian epigraphical tradition in Britain. Due to the exceptional origins of the manuscript and a number of uncommon features, the background of the material and the runic scribe are also examined.
\end{abstract}

Keywords: Runica manuscripta, Yorkshire, written runes, Scandinavian runic alphabet, Byland Bede, rune-like characters, manuscript runes

$\mathrm{R}$ ecently, a manuscript containing runes kept in the private collection of Sir John Paul Getty on his Wormsley estate in High Wycombe, Buckinghamshire, was brought to the attention of the present author. The estate is currently owned by his son Marc Getty, who continues his father's bibliophilic legacy. A brief description of the manuscript for an exhibition organised by the Pierpont Morgan Library in cooperation with Paul Getty in 1999 mentioned the runes but deemed them to be AngloSaxon (Fletcher et al. 2007, 8). The purpose of this article is to provide a full description of the manuscript and its runes and to consider the significance of this find within the context of English runica manuscripta and local epigraphy.

The manuscript is called the Byland Bede and, as the title indicates, contains two of Bede's works: the Latin commentary on the Acts of the Apostles, and commentaries on the Seven Canonical Letters and the Prologue of St Jerome. It was for the most part written by one scribe in 
Byland Abbey in Yorkshire, c. 1150-75, in a late-Romanesque English Cistercian book-hand (Fletcher et al. 2007, 8) although there are a number of occasional markings and notes which were made by at least three different hands. The catalogue notes that the most recent hand, probably from the late fifteenth or early sixteenth century, is responsible for the signature "- Bennett" on fol. 79v (Fletcher et al. 2007, 10). The present author is not convinced that this reading is correct. The first and the last vowel are differently shaped, making a name like "Barnett" equally possible. There is some very faint writing just before this name, but only the letters ' $\mathrm{Be}$ ' and ' $\mathrm{f}$ ' can be discerned. The contents of the manuscript are as follows:

1. Front flyleaf: Eight Anglo-Saxon abbreviations and idiosyncratic letter forms; Scandinavian runic alphabet; thirteen rune-like characters;

2. Fol. 1r-v: Divino in Christo desiderantissimo et uere beatissimo. Accae episcopo; beda perpetuam salutem;

3. Fols. 2-34r: Beda Venerabilis, Opusculum in Librum Actuum Apostolorum cum Expositione de Nominibus Locorum;

4. Fols. 34r-101v: Beda Venerabilis, Expositio in Septem Epistolas Canonicas.

As noted, the codex originates from the library of the Cistercian Abbey of the Blessed Virgin Mary at Byland, Yorkshire. This ownership is recorded at the top of fol. 1r: "Liber Sante Marie De Bellalanda". The formation of this abbey was the result of a long process beginning with a group of monks from the congregation of Savigny, led by Abbot Gerald, leaving their first monastery at Furness in Cumbria (established in 1128) to found a daughter monastery in Calder in 1135. This move was unsuccessful as Calder was ransacked by the Scots in 1138 and the monks were forced to return to Furness. They were denied entry, however, as Abbot Gerald was unwilling to relinquish his new title of abbot to the abbot of Furness (Burton 2006, 2). The monks sought help from Archbishop Thurstan of York who suggested contacting the nobleman Lord Roger de Mowbray; he granted them permission to stay at Hood in Yorkshire. The site did not, however, lend itself to the construction of a monastery, and in 1142 the monks were given Byland on the Moor by Lady Gundreda, the mother of Lord Roger (Burton 2006, 11). They began to build an abbey, later referred to as Old Byland, and moved there in 1143. Four years later, however, the monks transferred to Oldstead (Stocking), a wasteland also granted by Roger de Mowbray, where they built a small stone church and a cloister 
in order to escape the sound of the bells of nearby Rielvaulx Abbey. They remained on this site for thirty years before their final move to New Byland near Coxwold in 1177, during which period the community also joined the order of the Cistercians (Burton 2006, xxi). The manuscript was presumably written during this thirty-year period at Oldstead.

The abbey was suppressed by King Henry VIII in 1538 and the land was granted to Sir William Pickering, passing subsequently to the Wotton, Stapylton, and Wombwell families (Fletcher et al. 2007, 8). Only twentyseven manuscripts survive from the abbey's original collection. Based on the late fifteenth- or early sixteenth-century inscription, the codex may have belonged to a man named "Bennett" or "Barnett" during that time but there is no further information about this owner. The first known owner was Thomas Bateman of Lomberdale House (d. 1861), from Bakewell, Derbyshire. William Bateman inherited the codex which was then sold in 1893 during the Bateman Heirlooms sale by Sotheby's Auction House. Robert Hoe III (d. 1909) bought the manuscript and after his death it was again sold in 1911 by Anderson Auction House. It came into the possession of Thomas Jefferson Coolidge Junior before it was finally acquired by the Wormsley library in August 1997 (Fletcher et al. 2007, 10).

The runic material in this codex comprises a Scandinavian alphabet of twenty-one runes, a row of eleven runic and rune-like characters, and a final two characters underneath (fig. 1). The runes of the alphabet are situated in the middle of the front flyleaf beneath a row of AngloSaxon characters and are divided into two rows, $\mathrm{a}-\mathrm{o}$ and $\mathrm{p}-\mathrm{x}$ according to transliterations. The transliterations are provided in rows above the runes: the first line of transliteration appears on line 6 of the lead point ruling, the first line of runes on line 7 . The second line of transliterations appears on line 8 , followed by the second line of runes on line 9. Two empty lines are left between this second line and a line of eleven runes or rune-like characters. There is subsequently one further empty line, followed by two final characters for which neither transliterations nor additional information has been provided.

The alphabet is clear and well-drawn but contains a large amount of dotting. This appears to be of two types: dots in places which are typically dotted ( $\Psi, \uparrow$ for instance) and slightly less distinct dots which the scribe placed above the staves of certain runes (the $m$-rune and $e$-rune, for instance). The reason for the presence of the second type is unclear, although the difference between the two types of dotting facilitates recognition of scribal errors: the $a$-rune and the $t$-rune contain distinct dots, so the scribe probably considered these to be essential (though dots 


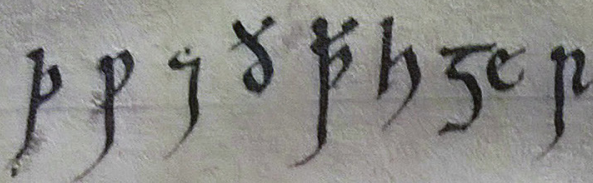

a b a c f $s$ hiklmn

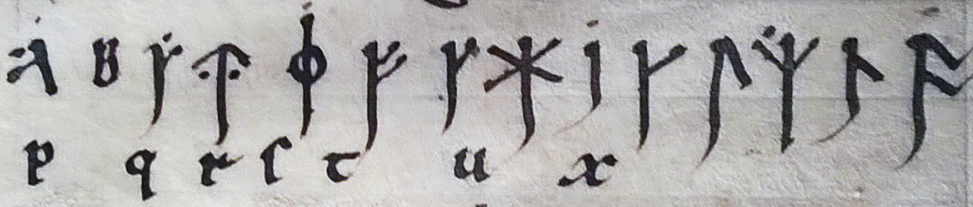

BरRit o

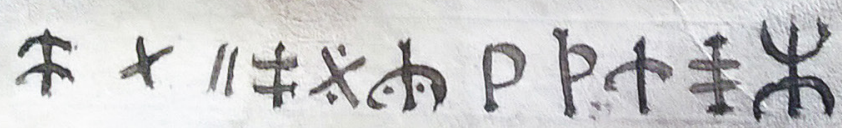

b)

Fig. 1. The front flyleaf of the Byland Bede. Photograph by the author with permission of the owner.

of the second type can also be seen above the staves). Small serifs appear at the top and bottom of the staves, giving the material a book-hand character and strong similarity to the script used for the Latin text in the codex. The following runes require some comment:

- The $a$-rune is dotted on the left-hand side and the branch does not cross the stave. The dot is likely to be a mistake but the shape of the $n$-rune indicates the intentional use of short-twig runes; 
- The rune transliterated as ' $c$ ' is a dotted $k$-rune and therefore technically a g-rune;

- The $d$-rune has been given two dots on either side of the stave of a double-branched $t$-rune;

- The $g$-rune here is not dotted and therefore technically a $k$-rune;

- For ' $k$ ' the same rune is used as for ' $g$ ', but the branch is longer and stretches further;

- The $\mathbf{m}$ is dotted on the left-hand side between the stave and the left branch;

- The character representing 'o' is interesting here as the rune is clearly Anglo-Saxon. It is perhaps conceivable that this is an exaggerated younger futhark $\mathbf{o}$ but the upwards curve at the end of the branches suggests otherwise;

- The rune representing 'q' here seems again to be a variant of the $k$-rune but the serifs at the top are more distinctive, making it similar to an insular 's';

- There appear to be two s-runes, short-twig and long-branch. The scribe, however, appears to have been unaware of difference or afterwards confused transliterations and placed these in the positions of 's' and ' $t$ ';

- The following character looks like a d, again with two branches, but with only one dot on the right-hand side. It is likely that this rune was meant to represent ' $t$ ' but, due to the confusion with the two $s$-runes, this character was transliterated as ' $u$ ';

- The final character is a very triangular-looking $u$-rune which is given the value ' $x$ ';

- The alphabet is missing ' $y$ ' and ' $z$ ', and the runic letters $æ$ and $\varnothing$ are not represented.

The runes are not easily classified, though they are probably medieval; this is also indicated by the twelfth-century dating of the Byland manuscript. A more detailed assessment of the material requires first determining with which tradition it should be compared. There are four manuscripts of a similar date within the English runica manuscripta tradition with which comparison is possible: Oxford, St John's College, MS 17; London, British Library, Cotton MS Domitian A. IX; Cambridge, Trinity College, MS R. 14.34; and London, British Library, Stowe MS 57 (for full descriptions and references of the manuscripts discussed here-unless otherwise indicated-see the author's Ph.D. thesis, Van Renterghem 2017). All four manuscripts are from the south of England: St John's MS 
17 from Thorney, MS Domitian A. IX from Worcester, Trinity MS R. 14.34 from Bury St Edmunds, and Stowe MS 57 from Peterborough. St John's MS 17 and Stowe MS 57 contain futharks in rune-row order while the other two present alphabetised rows of Scandinavian runes. Many similarities can be found between these rune-rows although their idiosyncrasies make clear that no immediate relationship can be construed between them. In general, a number of forms are distinctive in these twelfth-century rune-rows: (1) both the long-branch and short-twig forms of $\mathbf{a}$ and $\mathbf{n}$ are used; (2) both long-branch $\mathbf{s}$ and $\mathbf{k}$ are used for 'c'; (3) * and $\neq$ are both used for 'o'; (4) 'q' is represented by k; (5) both shorttwig and long-branch s are used; (6) both single- and double-branched t appear. The futharks are noteworthy here, as St John's MS 17 is the only manuscript to display exclusively the long-branch varieties of all runes, and Stowe MS 57 provides variants of most runes, so includes longbranch and short-twig runes. Stowe MS 57 notes the transliterations 'c' and 'q' for $Y$, which St John's MS 17 transliterates as 'c'; its rune-row does not include 'q'. The runic alphabets on the other hand tend to present mainly short-twig features. These discrepancies may be explained by the time difference, since St John's MS 17 was probably written in the early twelfth century and the others later in that century. When comparing these features with the Byland Bede, which is probably from the second half of the twelfth century, it is interesting to note that its features fall somewhere between the two groups. It provides $\mathbf{k}$ for 'c' like Domitian A. IX, St John's MS 17 and Stowe MS 57, notes both forms of $\mathbf{s}$ like Stowe MS 57, and gives a double-branched $\mathbf{t}$ like St John's MS 17 and Stowe MS 57. The similarities with Stowe MS 57 here, however, are mostly due to the collective nature of this manuscript, especially since the Byland Bede features an Anglo-Saxon o-rune, a confusion which does not occur in any of the other manuscripts. It may therefore be worthwhile examining the epigraphical tradition as well.

From an epigraphical point of view, two forms are of interest here: $\uparrow$ for ' $d$ ' appears around 1060 in Denmark but not before the late twelfth century in Norway (Page 1999, 209; never in this particular form, however), so this would suggest an East Norse influence on the Byland alphabet. A similar conclusion was drawn by R. I. Page and Jan Ragnar Hagland in reference to St John's MS 17, which contains the form with a cross-bar rather than dots $(1998,67)$. The second is the fourth rune of the futhark ('o' here; the fourth character of the futhark is given a number of different forms and values within the insular corpus, and for the sake of brevity, the character is here referred to as "the fourth rune" throughout). This rune 
is interesting as it also presents a problem in the epigraphical inscription from Sockburn (E 19, see Rye 2019) in County Durham, which shows an Anglo-Saxon F as the second letter of the name Mæl Muire instead of a suitable Scandinavian rune to match the rest of the inscription (although Rye here has read otherwise). This may of course be a coincidence, but Sockburn is located a mere thirty-five miles north of Byland Abbey, so a connection is possible. Eleanor Rye (2019), however, determined that the inscription is probably from the tenth or eleventh century, so clearly older than the Byland runes. Both sets of runes may still have similar origins and connections with East and West: Rye points out Sockburn's similarities with inscriptions from the Isle of Man and Cumbria, while (at least part of) the community responsible for the Byland codex lived at Furness Abbey in Cumbria for a number of years before moving to the east of the country. In fact, comparison with epigraphy makes it seem likely that the runic learning evident in this manuscript came from Furness (or the North-West more generally) rather than Byland or the North-East. The $\uparrow$ appears again in the inscription dotbrt on the thirteenth-century altar of Conishead Priory (E 11), which is located approximately nine miles from Furness Abbey (Barnes and Page 2006, 316-19).

The Bridekirk font (E 1) is also of interest here, since not only is it probably a twelfth-century work originating from Cumbria and containing an inscription in Scandinavian runes but it also contains a number of English book-hand features (Barnes and Page 2006, 281). Like the Byland Bede, it contains short-twig $\mathbf{a}$ and $\mathbf{s}$, as well as the double-branched $\mathbf{t}$. The inscription also shows the crossed form of the dotted $\mathbf{t}$ shape, although Michael P. Barnes and R. I. Page $(2006,281)$ concluded this was a bind-rune of $\mathbf{t}$ and $\mathbf{e}$. None of these elements is necessarily unusual, yet the appearance of "local" epigraphical features in the manuscript and the appearance of manuscript features in a "local" inscription during the same time period may be considered significant. The font does not in itself shed more light on the manuscript, nor is it possible to connect the two immediately, but the similarities between these three elements do support the likelihood that the Byland Bede runes have a place in the north-western tradition. Additionally, the font and the manuscript suggest that in this area, the delimitation between epigraphy and manuscripts was less pronounced. It is possible then that this area was subjected to heavy Danish influence which affected both carvers and scribes. The Thorney manuscript (St John's MS 17) may have experienced similar influence from the former Danelaw area. The confusion over the fourth rune, however, remains unsolved: the fourth rune used in Conishead is $\neq$, while Bridekirk employs 
₹ for 'o'. Perhaps then the appearance of two Anglo-Saxon fourth runes instead of Scandinavian ones from the same area is merely coincidence and attributable to scribal error. This mistake is, nonetheless, indicative of familiarity with the Anglo-Saxon rune-row, which is worth examining.

As the manuscript provides no information on the scribe, it may be beneficial to look in more detail at the other material on the page in order to gain some insight into his runic knowledge. The line of characters below the alphabet shows a curious mixture of "runes" which developed in the manuscript tradition, a number of runes found in both epigraphy and manuscripts, and a few apparently misunderstood characters. The final two characters at the bottom are probably the Roman letters ' $h$ ' and 'd' but with further unnecessary dotting. These additional characters all appear to be by the same hand, which uses a rounded script. It is worth noting that they are serifed differently to the alphabet and the colour of ink is slightly lighter. This suggests a different hand, though probably contemporary with the manuscript. The more haphazard structure and lack of transliterations further support this impression. It would seem that this second hand recognised the runic alphabet and added further material. The provision of "variant" or extra forms in a separate section by the same or other scribes is a common practice in manuscripts containing runes and often stems from the problems which arose in alphabetising the futhark (Derolez 1959, 4). It is worth taking a closer look at these characters as well:

- The first character could be a "coded" twig-rune (2/2). It also appears in two Continental manuscripts: St Gallen, Stiftsbibliothek, MS 878 has it for ' $\mathrm{k}$ ' and Munich, Bayerische Staatsbibliothek, CLM 14436 for 'i';

- The second and third characters look like they could potentially be division marks, used to separate elements in runic inscriptions/texts. It may be that this annotator thought they were runes and included them - this would indicate a lack of understanding of the material. Alternatively, they could also be an Anglo-Saxon g-rune and two $i$-runes, but the slightly slanted and nonchalant method of drawing makes this rather unlikely (especially in comparison with the $i$-rune from the alphabet, and the fifth character in the additional runic section);

- The fourth and penultimate character could be a (clumsily drawn) Scandinavian o-rune, though a similar shape appears for ' $\mathrm{t}$ ' in Bern, Burgerbibliothek, MS 207, for 'in' (rune-name inc) in manuscripts 
containing the isruna-code (for an in-depth discussion see Derolez 1954, 89-169), and for ' $k$ ' in London, British Library, Cotton MS Titus D. XVIII;

- The fifth character could be an Anglo-Saxon g-rune, again with unnecessary dotting;

- Then follows either an Anglo-Saxon m, or Scandinavian $y / R$-rune, again dotted;

- A wynn;

- A thorn;

- This character is unclear: it could be an a-rune, an exaggerated Scandinavian $e$-rune, or a $t$-rune with curved branches;

- The final rune of the row could be a poorly drawn $k$-rune, but the same character appears for ' $x$ ' in Exeter Cathedral Library, MS 3507, and Oxford, St John's College MS 17 (probably due to the similarity with the Roman letter ' $x$ '); it is also one of the golden numbers in the runic calendars.

Identifying the source of these additional runes is not straightforward, as none of the surviving manuscripts with runes contains all or even some of these characters together as a unit. The variety in the collection gives the impression that the annotator examined a number of manuscripts containing runes and selected runes which differed from the alphabet. This is possible, if somewhat impractical. The characters, most of which are Anglo-Saxon or appear in Anglo-Saxon manuscripts containing runes, point towards an Anglo-Saxon source. The most straightforward solution would therefore be that the annotator found his material in one of the aforementioned "extra" sections, such as appear in London, British Library, Cotton MS Vitellius A. XII, Exeter Cathedral Library, MS 3507, or London, British Library, Stowe MS 57. However, none of the runes for which parallels have been found in other manuscripts appears in these additional sections. A certain degree of variation exists between these sections, so it is of course possible to postulate the existence of a manuscript with these characters which is now lost. In fact, a number of these forms or similar forms do appear in a fourteenth-century manuscript from Whalley Abbey, Lancashire (Whitaker 1872, 181; Holman 2007, 191).

This manuscript, London, British Library, Additional MS 10374, also contains a Scandinavian alphabet and an "additional" section of characters, though with fewer mistakes in dotting and the alphabetic use of 4 for ' $c$ ' and ' for 's' (fig. 2). There is not enough overlap between the alphabets and additional characters for this to be a copy of the Byland 


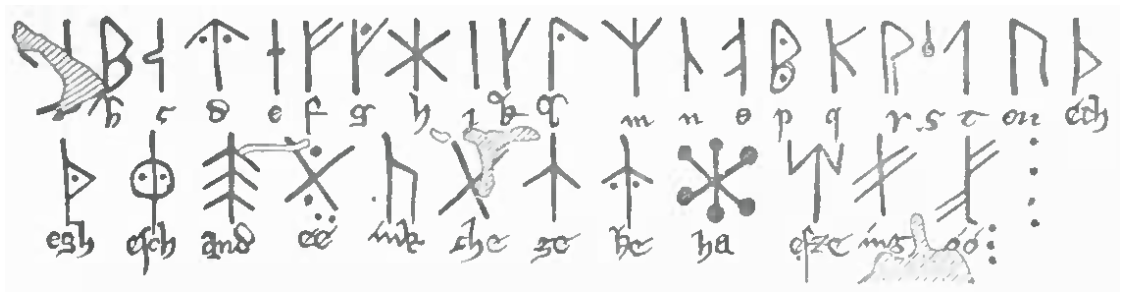

Fig. 2. The runes of London, British Library, Additional MS 10374, as copied by Whitaker $1872,181$.

Bede. Additional MS 10374 also contains a number of transliterations and rune-names which are not found in the Byland codex. This indicates the existence of (at least) a third copy of this material which was separately annotated. The rune-forms and the consideration that a second hand wrote the additional characters, possibly taken from an Anglo-Saxon manuscript containing runes, suggest that the Byland Bede was the first manuscript to contain the alphabet. The fly-leaf material was then afterwards copied as a whole, which explains the striking similarity with the fourteenth-century manuscript. In view of Bede's popularity, it is hardly inconceivable that the Byland manuscript was borrowed and copied. This copy (or even a copy thereof) may then have been the exemplar for the Whalley manuscript. Katharine Holman, who first remarked on the similarity between Additional MS 10374 and Conishead (see above) due to the appearance of the dotted $\mathbf{t}$ in both, could not find a direct connection between the monasteries of Whalley and Conishead (1996, 84; 2007, 191). It may be that there was no direct connection but that the appearance of this alphabet was a result of copying between manuscripts. The motivation behind the copying is not necessarily clear, however: the Whalley manuscript contains various charters and documents related to Whalley Abbey, its history and its surroundings, but no texts by Bede nor any other material indicative of a connection. Considering the location of the abbey and the use of Scandinavian runes on epigraphical monuments in the North-West, the copy may have been motivated by the recognition of the rune-forms as local elements, but this is tenuous at best. It is more likely that the connection lies in the unknown third manuscript.

One more element may add further depth to this discussion: at the top of the Byland front flyleaf nine characters appear which are clearly taken from insular Roman script. The first character is thorn; then wynn; then a Tironian note (dotted again); then eth; this is followed by the Anglo-Saxon abbreviation for $p æ t$; the letter 'h' (which seems the odd one out); then 
$y o g h+$ ' $\mathrm{e}$ ', thus 'ge-', which is often found at the beginning of Old English (and some Middle English) verbs; and finally the insular ' $r$ '. The scribe appears to have been interested in the vernacular way of writing, despite (or perhaps due to) his own writing in Latin. In the twelfth century, this may have been an effort to preserve the English way of writing against a backdrop of Anglo-Norman social dominance, or an Anglo-Norman scribe showing an interest in the English language or script. A similar selection of Anglo-Saxon letters can be found in Paris, Bibliothèque Nationale, MS Lat. 9666, an eleventh-century manuscript from Echternach, though this section contains only the Tironian note, wynn, eth, the abbreviation for $p æ t$, and in addition the ligature of 'a' and 'e', i.e. ' $æ$ '. The reason for the preservation of the material there is likely to be scholarly curiosity.

The hand appears to be the same for the Bede text as for the runic alphabet and the insular characters. The appearance of runic characters in manuscripts containing works by Bede is too frequent to be coincidental: an association between the scholar and this material clearly exists. Unfortunately, this reveals little regarding the background of the Byland rune-scribe, as this phenomenon occurred both in England (for instance Cambridge, Corpus Christi College, MS 41; Cotton MS Domitian A. IX; Cotton MS Vitellius A. XII; and St John's MS 17) and on the Continent (at least ten manuscripts, including the aforementioned St Gallen MS 878 and Munich, CLM 14436), in both Germanic and Romance-speaking areas. It is worth noting, however, that the runes in these Bede manuscripts are predominantly Anglo-Saxon. In fact, only Cotton Domitian A. IX contains a Scandinavian alphabet similar to that of the Byland manuscript, but this was a twelfth-century addition to the manuscript. The two other manuscripts which feature Bede as well as Scandinavian runes are St John's College MS 17 and St Gallen MS 878, both of which contain futharks.

As noted, the institution responsible for producing the manuscript belonged to the Savigny order (though officially Cistercian at the time of production), which originated in northern France on the borders of Normandy, Brittany, and Maine (Burton 2006, vii). The nationality of the monks who initially moved to Cumbria and later arrived at Byland was therefore probably Norman French, especially considering that Furness and Lancashire were given to Stephen de Blois, a Norman lord, by King Henry I in 1120 (Kapelle 1979, 200-02), and that he was responsible for founding the Savigniac house at Furness (King 2010). Additionally, Anglo-Norman was widely spoken in England in the twelfth century. Consequently, it is certainly conceivable that the monks were speakers of French or Anglo-Norman and that a number of them were educated on 
the Continent. The reason for some oddities in the manuscript may therefore be the scribe's Continental background. This may for instance explain the use of Scandinavian $\mathbf{k}$ for ' $\mathrm{c}$ ', which is common in the De Inventione Linguarum tract. It could be argued that this is also a feature of the alphabetised younger futhark, but there is only one remaining example of this, Paris, Bibliothèque Nationale, MS Lat. 9666, and this manuscript lacks the letter ' $\mathrm{k}$ ', preventing any firm conclusions in this regard.

The De Inventione Linguarum tract, attributed (probably incorrectly) to Hrabanus Maurus, contains a discussion of alphabets, mainly the Greek, Hebrew, Roman, Aethicus Ister (a fictional cosmographer from the early medieval work Cosmographia by the priest Hieronymus), and runic alphabets (Treffort 2013, 53). The runes included in this treatise are predominantly Anglo-Saxon, which makes the appearance of the single Scandinavian rune remarkable. Possible scribal familiarity with this material could explain the use of $\mathbf{k}$ for ' $c$ ' and the accidental use of the Anglo-Saxon o-rune. Such confusion should not necessarily be mistaken for ignorance, as the explanatory text in De Inventione Linguarum indicates that runes were part of the culture of the "Northmen", while providing an Anglo-Saxon runic alphabet as an example. This explanation, however, necessitates the scribe having a Continental background, as all extant $D e$ Inventione treatises with runes were produced on the Continent. Page and Hagland nonetheless drew a different conclusion in their study of the St John's College manuscript: they noted that use of different runes for ' $c$ ' and ' $k$ ' may have been due to the Anglo-Norman practice of distributing the sound according to the "palatal rule" $(1998,66)$. Unfortunately, due to the confusion with dotting, it is difficult to tell here if a differentiation has actually been made. Both options nevertheless suggest an Anglo-Norman origin. There may however also have been an awareness that ' $c$ ' was not part of the Scandinavian rune-row (as already indicated by some of the runica manuscripta above, ' $\mathrm{h}$ was used to create the parallel with Latin 'c'). That would for instance explain why the Bridekirk inscription also uses Scandinavian $\mathbf{k}$ where the Middle English text requires ' $c$ '.

The motivations behind the writing of the rune-row and insular characters may therefore not differ as much from Paris, Bibliothèque Nationale, MS Lat. 9666 as originally thought: the inclusion of this material may show an interest in English (local) culture, perhaps fuelled by admiration of Bede and his reputation as a scholar of the history of Britain. The association with Bede may have prompted the Anglo-Norman scribe to record the English characters and inspired the collection of runes and alphabets, which were then sourced locally. The 
fact that Scandinavian runes were readily available, as indicated by the post-Conquest epigraphical inscriptions, further confirms the persistence of the Scandinavian language and identity in the north of England (Page 1995, 189).

The existence of this manuscript is also significant within the context of English manuscripts containing runes. Although English scribes show no lack of interest in Scandinavian runes, no other manuscript runes originate from Yorkshire (or Cumbria). Twelve manuscripts with Scandinavian runes were produced in England between the ninth and the fifteenth century, of which one, London, British Library, Cotton MS Galba A. II, no longer exists. Its origins cannot therefore be determined. It is remarkable that, prior to discovery of the Byland Bede, no manuscripts with runes written in the north of England had been found. Although not all runica manuscripta are southern English productions, with London, British Library, Harley MS 2399 possibly being written in Cornwall, and Oxford, Bodleian Library, MS 572 potentially in Wales, none has an origin further north than the Midlands. Later, in the thirteenth century, Oxford, Bodleian Library, MS Junius I (better known as the Junius Orrmulum) was created in Lincolnshire and in the fourteenth, British Library, Additional MS 10374 in Lancashire, but it seems that runic interest in the North only really began in the twelfth century. Although there is no impediment to a "southern" phenomenon which then moved north after the Conquest, or even an interest born of Anglo-Norman curiosity, it is strange that no notice was paid to this material earlier in the northern scriptoria which were certainly no strangers to the Vikings and Scandinavian culture.

For the sake of completeness, it should be added that these are not the only runes produced before the twelfth century in the scriptoria of the North. Two well-known manuscripts, the Lindisfarne Gospels and the Durham Psalter received Old English glosses by the scribe Aldred, a monk and later provost from the community of St Cuthbert in Chester-le-Street, in present-day County Durham (Jolly 2012, 52 f., 74). In his glosses, this monk frequently employed Anglo-Saxon runes, though only a limited number, and their use was restricted to abbreviations for Old English words ( $\boldsymbol{A}$ for mann, $\boldsymbol{X}$ for $d æ g$ ). This material, however, is approximately two centuries older than the Byland Bede, with a tenth-century dating (Brown 2011, 36; Jolly 2012, 66-70). Aldred's use of runic abbreviations is somewhat haphazard, because though consistent in how he uses the runic abbreviations, he also writes those same words in full on some occasions (Lendinara 2016, 357). This may therefore indicate more of a playful interest than a committed use of the rune-row. Moreover, since these 
two Anglo-Saxon manuscripts were annotated by the same scribe, and the information for the Byland Bede material probably originated from the west of the country, there seems little reason to suspect a hitherto undiscovered runic tradition in that part of England.

In conclusion, while the find of a new manuscript is always of great interest, this manuscript is of particular value. As the first manuscript containing Scandinavian runes from the area, it confirms that despite or perhaps thanks to Norman French dominance, Anglo-Scandinavian culture in the North managed to penetrate monastic walls. The find of this manuscript also allows for a comparison with (local) epigraphical material which indicates reciprocal communication between the two elements. The combination of epigraphical elements and manuscript lore demonstrates that both manifestations of runic writing, written and carved, can occur in conjunction. Thus the manuscript offers a promising impetus towards a more balanced examination of both sources in the future.

\section{Bibliography}

Barnes, Michael P., and R. I. Page. 2006. The Scandinavian Runic Inscriptions of Britain. Runrön, 19. Uppsala.

Brown, Michelle P. 2011. The Lindisfarne Gospels and the Early Medieval World. London.

Burton, Janet. 2006. The Foundation History of the Abbeys of Byland and Fervaulx, Borthwick Texts and Studies, 35. York.

Derolez, René. 1954. Runica Manuscripta: The English Tradition. Faculteit van de letteren en wijsbegeerte, Rijksuniversiteit te Gent, Werken, 118. Brugge.

—. 1959. "Die 'Hrabanischen' Runen.” Zeitschrift für deutsche Philologie 78: $1-19$.

$\mathrm{E}+$ no. between 1 and 16 = inscription from England published in Barnes and Page 2006.

Fletcher, H. G., R. J. D. Harding, B. D. Maggs, W. M. Voelkle, and R. S. Wieck. 2007. The Wormsley Library: A Personal Selection by Sir Paul Getty. Ed. H. George Fletcher. 2nd ed. London.

Holman, Katherine. 1996. Scandinavian Runic Inscriptions in the British Isles: Their Historical Context. Senter for middelalterstudier, Skrifter, 4. Trondheim.

— . 2007. The Northern Conquest: Vikings in Britain and Ireland. Oxford.

Jolly, Karen Louise. 2012. The Community of St. Cuthbert in the Late Tenth Century: The Chester-le-Street Additions to Durham Cathedral Library A.IV.19. Columbus, $\mathrm{OH}$.

Kapelle, William E. 1979. The Norman Conquest of the North: The Region and Its Transformation, 1000-1135. Chapel Hill, NC. 
Ker, Neil R. 1957. Catalogue of Manuscripts Containing Anglo-Saxon. Oxford.

King, Edmund. 2010. "Stephen (c. 1092-1154)." In Oxford Dictionary of National Biography. Oxford, 2004. Available online at: https://doi.org/10.1093/ ref:odnb/26365 (accessed April 2017).

Lendinara, Patrizia. 2016. "The 'Unglossed' Words of the Lindisfarne Gospels." In The Old English Gloss to the Lindisfarne Gospels: Language, Author, and Context, ed. Julia Fernández Cuesta and Sara M. Pons-Sanz, 329-59. Berlin.

Page, R. I. 1995. Runes and Runic Inscriptions. Woodbridge.

—. 1999. An Introduction to English Runes. 2nd ed. Woodbridge.

Page, R. I., and Jan Ragnar Hagland. 1998. "Runica Manuscripta and Runic Dating: The Expansion of the Younger Fupark." In Innskrifter og datering / Dating Inscriptions, ed. Audun Dybdahl and Jan Ragnar Hagland, 55-72. Senter for middelalderstudier, Skrifter, 8. Trondheim.

Rye, Eleanor. 2019. "A New Runic Inscription from Sockburn Hall, County Durham: E 19 Sockburn.” Futhark 8 (2017): 89-110.

Treffort, Cécile. 2013. "De Inventoribus Litterarum: The History of Writing as Seen by Carolingian Scholars." SVMMA: Revista de Cultures Medievals (Barcelona) 1: 43-58.

Van Renterghem, Aya M. S. 2017. "The Written Rune: Rune-Rows and Alphabets in Medieval Manuscripts from the Continent and the British Isles." Ph.D thesis, University of Nottingham. Nottingham.

Whitaker, Thomas Dunham. 1872. An History of the Original Parish of Whalley and Honor of Clitheroe. 4th ed.; rev. John Gough Nichols and Ponsonby A. Lyons. Manchester. 
